\title{
THE FUNDAMENTAL INEQUALITY FOR ALGEBROID FUNCTIONS ON ANNULI CONCERNING SMALL ALGEBROID FUNCTIONS
}

\author{
HONG YAN XU AND ZHAO JUN WU
}

Abstract. The main aim of this article is to study the properties on value distribution of algebroid functions on annulus. We obtain the second fundamental theorems for algebroid function concerning small algebroid functions on annulus, which improves the previous result given by Tan [28].

Mathematics subject classification (2010): 32C20, 30D45.

Keywords and phrases: Algebroid function, small algebroid functions, annuli.

\section{REFERENCES}

[1] S. AXLER, Harmomic functions from a complex analysis viewpoit, Amer. Math. Monthly 93 (1986), $246-258$.

[2] T. B. CAO, H. X. Y I AND H. Y. XU, On the multiple values and uniqueness of meromorphic functions on annuli, Comput. Math. Appl. 58 (2009), 1457-1465.

[3] X. K. Chang, S. Y. LiU, P. J. ZHAO AND X. LI, Convergent prediction correction-based ADMM for multi-block separable convex programming, Journal of Computational and Applied Mathematics, 335 (2018), 270-288.

[4] A. FERnÁndeZ, On the value distribution of meromorphic function in the punctured plane, Mat. Stud. 34 (2010), 136-144.

[5] W. K. Hayman, Meromorphic Functions, The Clarendon Press, Oxford, 1964.

[6] Y. Z. HE AND I. LAINE, On the growth of algebroid solutions of algebraic differential equations, Math. Scand. 58 (1) (1986), 125-138.

[7] Y. Z. HE AND X. Z. XIAO, Algebroid functions and ordinary differential equations in the complex domain, Beijing: Science Press, 1988.

[8] K. L. Hiong, Several recent studies of meromorphic functions (in Chinese), Adv. Math. (China), 6(1963), 307-320.

[9] K. L. Hiong, Sur les fonctions meromorphes et les fonctions algebroides, Mem. Sci. Math. GauthierVillars, 1957.

[10] A. Ya. Khrystiyanyn And A. A. Kondratyuk, On the Nevanlinna theory for meromorphic functions on annuli. I, Mat. Stud. 23 (1) (2005), 19-30.

[11] A. Ya. KhrystiYANYn And A. A. Kondratyuk, On the Nevanlinna theory for meromorphic functions on annuli. II, Mat. Stud. 24(2) (2005), 57-68.

[12] A. A. KondratyUK AND I. LAINE, Meromorphic functions in multiply connected domains, Laine, Ilpo (ed.), Fourier series methods in complex analysis. Proceedings of the workshop, Mekrijärvi, Finland, July 24-29, 2005. Joensuu: University of Joensuu, Department of Mathematics (ISBN 952-458888-9/pbk). Report series. Department of mathematics, University of Joensuu 10, 9-111 (2006).

[13] R. KorhOnen, Nevanlinna theory in an annulus, value distribution theory and related topics, Adv. Complex Anal. Appl. 3 (2004), 167-179.

[14] Y. Y. Kong AND D. C. Sun, Algebroidal function and its derived function in unit circular disc, Acta Math. Sci. 29 B (1) (2009), 129-139.

[15] L. W. LiAO AND C. C. YANG, Some new and old (unsolved) problems and conjectures on factorization theory, dynamics and functional equations of meromorphic functions, J. Jiangxi Normal University (Natural Sciences),41 (2017), 242-247. 
[16] H. F. LIU AND D. C. SUn, On the sharing values of algebroid functions and their derivatives, Acta Math. Sci. 33 B (1) (2013): 268-278.

[17] Y. N. LÜ AND X. L. ZhANG, Riemann surface, Science Press, Beijing, 1997 (in Chinese).

[18] M. Lund And Z. Ye, Logarithmic derivatives in annuli, J. Math. Anal. Appl. 356 (2009), 441-452.

[19] M. LuND AND Z. YE, Nevanlinna theory of meromorphic functions on annuli, Sci. China. Math. 53 (2010), 547-554.

[20] R. Nevanlinna, Zur Theorie der meromophen Funktionen, Acta Math. 45 (1925), 1-9.

[21] G. RÉmoundos, Extension aux fonctions algébroides multipliformes du théorème de M. Picard et deses généralisations, Mém. Sci. Math. fase Paris, Gauthier-Villar, 1927.

[22] M. RU, Algebroid functions, Wirsing's theorem and their relations, Math. Z. 233 (1) (2000), 137-148.

[23] M. RU, The recent progress in Nevanlinna theory, J. Jiangxi Normal University (Natural Sciences), 42 (2018), 1-11.

[24] H. L. SELBeRg, Über die Wertverteilung der algebroiden Funktionen, Math. Z., 31 (1930) 709-728.

[25] N. Steinmetz, Eine Verallgemeimerung des zweiten Navanlinnaschen Hauptsatzes, J. Reine Angew. Math. 386 (1986), 134-141.

[26] D. C. Sun And Z. S. Gao, Value distribution theory of algebroid functions, Beijing: Science Press, 2014.

[27] D. C. Sun And Y. Y. Kong, The growth of algebroid function, J. Math. Anal. Appl. 332 (1) (2007), $542-550$.

[28] Y. TAN, Several uniqueness theorems of algebroid functions on annuli, Acta Math. Sci. 36 B (1) (2016), 295-316.

[29] E. UlLRICH, Über den Einfluss der Verzweigtheit einer Algebroide auf ihre Wertverteilung, J. rei. u. ang. Math. 167 (1931) 198-220.

[30] G. VAliron, Sur quelques propriétés des fonctions algébrö̈des, C. R. Acad. Sci. Paris, 189 (1929), 824-826.

[31] G. Valiron, Sur la derivèe des fonctions algébroïdes, Bull. Sci. Math. 59 (1931), 17-39.

[32] N. Wu AND Z. X. XUAN, On T points of algebroid functions, Math. Slovaca 62 (1-2) (2012), 39-48.

[33] Z. J. WU AND D. C. SUn, On a singular direction of a meromorphic function, Georgian Math. J. 12 (3) (2005), 551-559.

[34] Z. J. Wu AND D. C. Sun, On T direction of algebroid function dealing with multiple values, Bull. Aust. Math. Soc. 78 (1) (2008), 147-156.

[35] H. Y. XU AND Y. Y. KONG, The approximation of Laplace-Stieltjes transformations with finite order on the left half plane, Comptes Rendus Mathematique 356 (2018), 63-76.

[36] H. Y. XU AND Z. X. XUAN, The uniqueness of analytic functions on annuli sharing some values, Abstr. Appl. Anal. 2012 (2012), Article ID 896596, 13 pages.

[37] H. Y. XU AND Z. J. WU, The inequality and its application of algebroid functions on annulus concerning some polynomials, Publ. Math. Debrecen 94 (2019), 269-287.

[38] Z. X. XUAn, On the existence of T-direction of algebroid functions: a problem of J. H. Zheng, J. Math. Anal. Appl. 341 (1) (2008), 540-547.

[39] Z. X. XUAN AND Z. S. GAO, On the Nevanlinna direction of algebroid function dealing with multiple values, J. Math. Anal. Appl. 325 (2007), 268-278.

[40] L. YANG, Value distribution theory, Springer-Verlag, Berlin(1993).

[41] H. X. YI AND C. C. YANG, Uniqueness theory of meromorphic functions, Kluwer Academic Publishers, Dordrecht, 2003; Chinese original: Science Press, Beijing, 1995.

[42] J. H. Zheng, Value Distribution of Meromorphic Functions, Tsinghua University Press, Beijing, Springer, Heidelberg, 2010. 